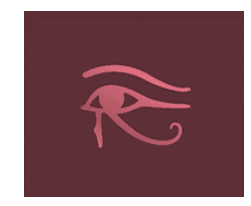

\title{
OS MODELOS ESCOLARES DE EDUCAÇÃO DE JOVENS, ADULTOS E IDOSOS NA CIDADE DE SÃO PAULO:
}

REFLEXÕES SOBRE DEMANDAS E OFERTAS

\author{
Vanessa Elsas \\ vanessa.elsas@ifsc.edu.br \\ Instituto Federal de Santa Catarina
}

RESUMO: O artigo socializa reflexões sobre a distância entre a demanda e a oferta da Educação de Jovens e Adultos na cidade de São Paulo, a partir da dissertação de mestrado - "A Trajetória do Projeto CIEJA entre as políticas públicas de EJA na cidade de São Paulo", desenvolvida no Programa de Pós-graduação em Educação da Universidade de São Paulo. Aborda-se a queda nos números de matrículas da EJA e os modelos escolares existentes para a modalidade, com foco nos Centros de Educação de Jovens e Adultos (CIEJA) e nos avanços e desafios permanentes para concretização do direito à educação. PALAVRAS-CHAVE: EJA, organização escolar, políticas públicas de educação.

\section{YOUTH AND ADULT EDUCATION IN SAO PAULO: REFLECTIONS ON THE DEMAND AND OFFERS}

\begin{abstract}
This article socializes reflections over the distance gap between the offering and demand enrollments for Adult's Education in the city of São Paulo, based on the master's thesis “The CIEJA project path between the public policies for Adult Education in the city of São Paulo". It approaches the decrease of Adult Education enrollments and the existing school models for this modality, focusing on CIEJA progress and over the continuing challenges to achieve the right to education.

KEY WORDS: Youth and adult education, School Organization, Public Education Policies.
\end{abstract}




\section{Introdução}

Ao longo da história, não raramente, o analfabetismo tem sido abordado como uma "chaga" a ser "erradicada" no país, associado ao sentimento de "vergonha" nacional e, muitas vezes, ao assistencialismo. Apesar dos discursos bastante inflamados e pouco reflexivos, a Educação de Jovens e Adultos (EJA) tem ocupado reiteradamente um papel secundário entre as políticas públicas de educação, conforme a aposta de que sua relevância e necessidade diminuiriam ao longo dos anos, à medida que as questões de acesso ao ensino básico fossem equacionadas desde a infância.

Diante dessa visão simplista sobre a EJA e da concepção da modalidade como mera questão de reposição ou aceleração de estudos, permanece o insistente cenário de analfabetismo e baixa escolaridade dos brasileiros. No Brasil, há cerca de treze milhões de pessoas com quinze anos ou mais consideradas analfabetas (IBGE, 2012); em 2010, quase a metade da população brasileira (49,25\%), com 25 anos ou mais, não tinha o Ensino Fundamental completo (IBGE, 2012).

Ainda assim, na cidade de São Paulo, bem como ocorre em outras localidades do país, diferentes atores influentes na definição de políticas públicas, de gestores escolares a técnicos de ensino nos gabinetes da Secretaria Municipal de Educação, chegam a negar, em diversos períodos da história, a existência de demanda significativa de jovens, adultos e idosos pela escolarização, para justificar sua baixa oferta nos sistemas públicos de ensino, relegando à EJA um território instável e de improvisação. Com políticas e financiamentos inconstantes, a EJA tem sido concebida à margem das ações educativas dirigidas aos infantes e adolescentes (DI PIERRO, 2008).

De um lado, uma suposta baixa procura dos trabalhadores jovens e adultos pelo ensino responderia ao fechamento de turmas e mesmo ao encerramento da modalidade EJA em algumas escolas do município paulistano, sem a devida avaliação e reflexão sobre os modelos escolares propostos.

De outro lado, pesquisadores do campo da EJA e de Educação Popular têm destacado reiteradamente a educação de jovens, adultos e idosos como direito, reconhecendo sua importância não só para maior inclusão de trabalhadores-estudantes, mas para o desenvolvimento econômico, político, cultural e social do país. (BEISIEGEL, 1974; GÓES, 1980; BRANDÃO, 1984; DI PIERRO, 2001; HADDAD, 2007; GADOTTI, 2009). 
Os modelos escolares de Educação de Jovens, Adultos e Idosos na cidade de São Paulo: Reflexões sobre demandas e ofertas

As pesquisas apontam ser necessário incluir, entre as pautas dos gestores públicos, o debate sobre a continuidade das dificuldades de acesso das pessoas com quinze anos ou mais às escolas e as condições da oferta educativa que favoreça sua permanência nos estudos, além dos processos de aprendizagem significativos para seu trabalho, identidade e emancipação.

Mais do que retratar os dados sobre a falta de ou baixa escolarização dessa parcela populacional, é necessário também reconhecer suas características e expectativas, a fim de superar a distância entre a demanda e a oferta, iluminando formas de estreitá-la.

Este artigo pretende contribuir com esse debate e refletir sobre essa distância, analisando as especificidades da demanda e oferta da EJA na rede municipal de São Paulo, a partir dos resultados da pesquisa de mestrado "A trajetória do Projeto CIEJA entre as políticas públicas de EJA na cidade de São Paulo”, debruçada sobre o período de 2001 a 2012 e finalizada em 2014.

A pesquisa apontou que as políticas municipais para a modalidade são formuladas, executadas e avaliadas a partir de mudanças no cenário das políticas públicas federais e das trocas de governo, com diferentes projetos e concepções de educação. São nesses momentos que se abrem as "janelas de oportunidades", para a atuação e proposição de alternativas de diferentes grupos e sujeitos políticos para resolução de um problema histórico: como fazer a EJA na cidade?

Avaliou-se que, entre os diversos sujeitos envolvidos no desenvolvimento das políticas públicas de EJA no município, professores, gestores escolares, supervisores e técnicos de ensino podem exercer papel fundamental para a manutenção ou a mudança das formas de ofertá-la. Concluímos, também, que a gestão democrática pode e deve ultrapassar a administração das unidades escolares e recuperar sua "radicalidade política" (ARROYO, 2008), de modo a alcançar todas as instâncias dos sistemas de ensino. Dessa maneira, seria possível a formação de políticas do tipo "botton up", que partem das experiências e necessidades concretas daqueles que vivenciam as dificuldades e abrem caminhos para superá-las nas escolas.

A partir da análise das políticas de EJA e das propostas de ensino existentes em diferentes governos desde 1989 até 2012, tecemos a história do Projeto dos Centros Integrados de Educação de Jovens e Adultos (CIEJA) e avaliamos seu modelo escolar, seus avanços e desafios diante das demais propostas educativas municipais para jovens, adultos e idosos. 
Na primeira parte do artigo, pretendemos socializar os dados coletados sobre a demanda potencial pela EJA, no Município de São Paulo, com vista a demonstrar a diferença entre as pessoas que necessitam acessar a escolarização e sua presença nas salas de aula.

$\mathrm{Na}$ segunda parte, expomos, sucintamente, as diversas propostas educativas municipais ofertadas para EJA e abordadas na pesquisa. Já na última parte, apresentaremos as considerações finais, com algumas pistas encontradas em nosso estudo, que podem iluminar ações necessárias para efetivar o direito à educação a jovens, adultos e idosos, a fim de garantir condições para sua presença, nas propostas educativas.

\section{Aspectos da demanda pela EJA na cidade de São Paulo: perfil dos educandos}

No Município de São Paulo, em 2010, havia 281.847 pessoas com quinze anos ou mais consideradas analfabetas, porque não sabiam ler ou escrever um bilhete simples (IBGE, 2012). Os números são argumentos definitivos contra a justificativa de que não haveria demanda pela EJA na cidade. O mapa a seguir apresenta a distribuição da taxa de pessoas na mesma faixa etária, que não concluíram o Ensino Fundamental no mesmo ano. 


\section{Mapa 1 - São Paulo: População de 15 anos e mais com Ensino Fundamental completo.}
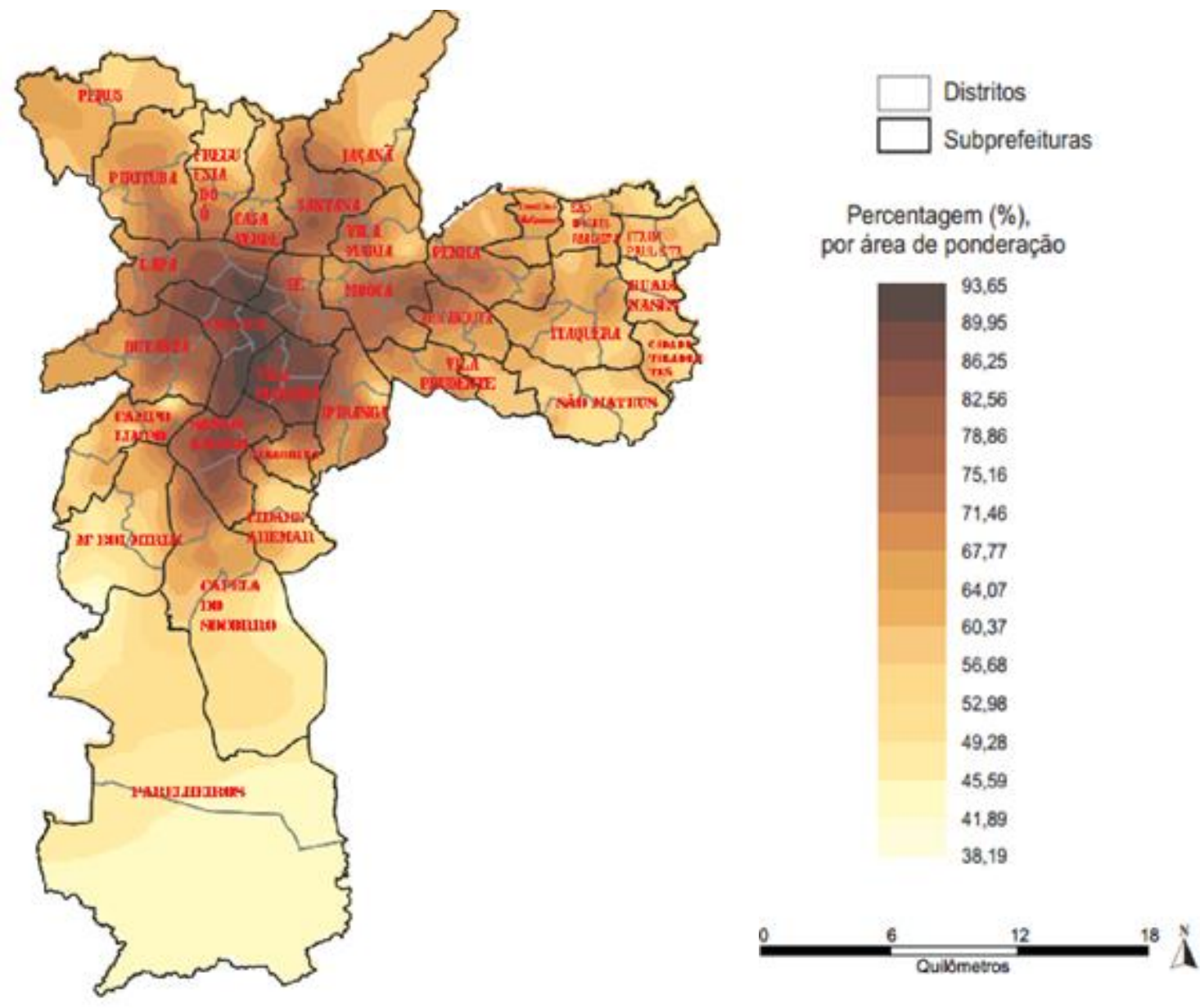

Fonte: Elaboração: Secretaria Municipal de Desenvolvimento Urbano - SMDU/ Departamento de Produção e Análise de Informação - DEINFO. IBGE. Censo Demográfico, 2010

O que poderemos observar é que as periferias concentram as piores taxas de escolarização, acompanhando outras formas de exclusão e precariedade na concretização de outros direitos, já que a maior quantidade de equipamentos culturais e de serviços públicos essenciais está nas zonas centrais, onde também encontramos maior renda per capita e maior taxa de empregos (GRINKRAUT et. al., 2013, p.35).

O mesmo ocorre com a taxa de analfabetismo na cidade: as periferias concentram o maior número de pessoas com quinze anos ou mais consideradas analfabetas. Conforme o Plano Nacional de Direitos Humanos (versão 3), os direitos devem ser considerados universais, indivisíveis e interdependentes. Isso significa que "sempre que um direito é violado, rompe-se a unidade e os demais direitos são comprometidos" (BRASIL.SECRETARIA DE DIREITOS HUMANOS/PNDH-3, 2010, p.16). Os dados 
reiteram, portanto, a vulnerabilidade e a exclusão de sujeitos de direitos que, sem acesso à escolarização, permanecem à margem da sociedade de cultura letrada.

Apesar dos dados incontestáveis sobre a existência da demanda pela EJA, na primeira década do século XXI, o número de matrículas de jovens, adultos e idosos na modalidade oscilou negativamente na cidade, como demonstra o quadro a seguir.

Tabela 1- Evolução das Matrículas ${ }^{1}$ no Ensino Fundamental de Jovens e Adultos por Dependência Administrativa no Município de São Paulo (2000/2012)

\begin{tabular}{lcccc}
\multicolumn{1}{c}{ Ano } & $\mathbf{2 0 0 0}$ & $\mathbf{2 0 0 4}$ & $\mathbf{2 0 0 8}$ & $\mathbf{2 0 1 2}$ \\
\hline Total & 248988 & 281063 & 259386 & 139753 \\
Estadual & 75706 & 115844 & 139107 & 75257 \\
Municipal & 133580 & 149662 & 113676 & 60586 \\
Privada & 39702 & 15557 & 6603 & 3910 \\
\hline
\end{tabular}

Fonte: Censo Escolar MEC/Inep e Centro de Informações Educacionais da Secretaria de Estado da Educação.

Tabela Adaptada de Infocid@ade/SMDU/Dipro/PM.

Enquanto a taxa de analfabetismo caiu de 4,5 para 3,2\% entre 2000 e 2010 na cidade, a tabela indica a drástica diminuição de 43,8\% nos números de matrícula na EJA, no nível do Ensino Fundamental, em pouco mais de dez anos. Na rede municipal de ensino, houve um decréscimo de 59,5\% no período. Mas por que as pessoas sem escolaridade não estariam se matriculando nos cursos de EJA?

Antes de responder essa questão, que procuraremos elucidar ao longo do artigo, é preciso lançar o olhar para quem são esses sujeitos, quais são suas características e condições de vida, pois, se a oferta da EJA é obrigatória para o Estado, as matrículas são facultativas para as pessoas, que possuem diversas motivações para buscar ou se afastar das escolas.

As pesquisas sobre o perfil desses estudantes na rede municipal de ensino de São Paulo são poucas, ora realizadas pela comunidade acadêmica, ora pelos próprios órgãos municipais, como forma de avaliar e subsidiar mudanças nas políticas voltadas para a modalidade. Verifica-se a carência de pesquisas sistemáticas, ou seja, com os mesmos parâmetros para coleta e sistematização dos dados. Esse fato dificulta a observação mais

\footnotetext{
${ }^{1} \mathrm{O}$ número de matrículas, baseado nas fontes citadas nessa tabela, divergem dos números apresentados pelo Relatório Anual de Fiscalização do Tribunal de Contas do Município em 2009, o qual aponta menos matrículas entre 2006 e 2009, baseado no Relatório de Dados Gerenciais SME-ATP/CI.
} 
Os modelos escolares de Educação de Jovens, Adultos e Idosos na cidade de São Paulo: Reflexões sobre demandas e ofertas

apurada sobre os estudantes e a formulação de políticas públicas abrangentes e afinadas às realidades presentes.

Dessa forma, em nosso estudo de mestrado, procuramos cruzar e analisar informações de diferentes fontes, selecionando o Relatório de Pesquisa Caracterização dos alunos dos CEMES (DOT-EJA/SENAC-SP, 2002), o documento Traçando o perfil de alunos e professores da EJA (SME, 2004) e dados de matrícula nos CIEJA, em 2012 e 2013.

A primeira observação sobre o perfil dos estudantes da EJA deixa claro que a diversidade é uma marca desses sujeitos, seja em relação à sua origem, faixa etária, etnia, gênero ou trabalho, no entanto guardam certa identidade de classe.

As pesquisas revelam que boa parte dos estudantes são migrantes, sendo que, entre os que possuíam 25 anos ou mais, apenas $25 \%$ havia nascido na região metropolitana de São Paulo. De acordo com o Relatório de Pesquisa Caracterização dos alunos dos CEMES, em 2002, cerca de 70\% dos estudantes vinham de Centros menores, dos quais aproximadamente $50 \%$ eram do Norte e do Nordeste, em especial da Bahia e de Pernambuco (SÃO PAULO, DOT-EJA/SENAC-SP, 2002).

As regiões Norte e Nordeste do país ainda apresentam os maiores índices de analfabetismo do Brasil (IBGE, 2012), refletindo na baixa escolaridade dos migrantes na cidade de São Paulo. A origem desses jovens e adultos nos revela mais que a desigualdade entre as oportunidades educacionais e econômicas no país, que persiste há décadas. Os alunos migrantes carregam costumes, saberes e vivências de cidades menores que enfrentam, muitas vezes, dificuldades de adaptação com o outro, com os ritmos de vida e trabalho na metrópole.

O tempo de escolaridade dos jovens e adultos antes de frequentarem os cursos de EJA também demonstra a persistência das condições precárias de acesso e permanência nas escolas, e a repetida negação do direito à educação a essa parcela da população. Conforme o Relatório de Pesquisa Caracterização dos alunos dos CEMES, dos estudantes que possuíam escolaridade anterior ao ingresso nos cursos, 36\% interromperam os estudos havia mais de onze anos e $30 \%$ interromperam estudos havia cinco anos ou menos (SÃO PAULO, DOT-EJA/SENAC-SP, 2002).

Em relação às ocupações no trabalho, o Relatório indicava que $63 \%$ dos estudantes trabalhavam fora, sendo que $75,3 \%$ eram homens e 53,8\%, mulheres. Dentre os alunos trabalhadores, 49,5\% tinham carteira assinada e 32,5\% não possuíam registro. Dos empregados e autônomos, $8 \%$ não declararam se a relação de trabalho era 
formalizada. Quanto ao rendimento, 32\% dos estudantes possuíam rendimento de 1 a 2 salários-mínimos e $24 \%$ de 2 a 3 salários mínimos ${ }^{2}$. Destacava-se, ainda, que $36 \%$ não estavam ocupados, incluídos os desempregados, as donas de casa, aqueles que não haviam ingressado no mercado de trabalho, os aposentados, licenciados por doença, os que recebiam algum tipo de benefício de programas governamentais e os que não responderam. (SÃO PAULO, DOT-EJA/SENAC-SP, 2002)

A pesquisa Traçando o perfil de alunos e professores da EJA (SME, 2004) revela a continuidade dessa realidade. A maioria dos estudantes (74\%) que responderam à pesquisa de 2004 estava trabalhando ou em busca de trabalho. O desemprego atingia um percentual de $33 \%$ entre os respondentes. Dos que estavam trabalhando, mais de um terço (39\%) não tinha registro de empregado ou autônomo, atuando no mercado informal, sem os direitos garantidos pela legislação. A maioria dos que trabalhavam (43\%) ganhava de 1 a 2 salários-mínimos e outros $33 \%$ ganhavam mais de 2 a 5 salários mínimos ${ }^{3}$.

Entre os motivos para abandonar os estudos, $46 \%$ indicaram a necessidade de trabalhar, $12 \%$ apontaram experiências negativas na escolaridade anterior e 1\%, a necessidade de cuidar da família.

$\mathrm{O}$ afastamento dos estudantes, devido às necessidades do trabalho, coloca em pauta tanto a formulação de propostas educativas mais flexíveis e sensíveis às horas disponíveis para o estudo, quanto a necessidade de fazê-las dialogar com seus saberes e necessidades de formação profissional para a melhoria das condições de vida.

Em relação à faixa etária, a pesquisa apontou que $43 \%$ dos estudantes tinham até 25 anos, e $28 \%$ tinham entre 25 e 35 anos, dado que coincide com o período de buscar o primeiro trabalho ou melhores oportunidades profissionais. Segundo o Estatuto da Juventude, Lei 12.852/2013, são consideradas jovens as pessoas entre 15 e 29 anos. O número de jovens que não completam a escolaridade também se relaciona ao denominado "fracasso escolar".

Isso é preocupante porque a grande maioria desses jovens analfabetos são pessoas que passaram pela escola, que tiveram uma trajetória escolar marcada pela repetência, pela evasão, que vão e voltam ao sistema de ensino e não conseguem se apropriar da ferramenta da leitura e escrita. Esse é um indicador muito forte de que a escola está fracassando perante um grupo grande de jovens e este grupo concentra uma maioria de pessoas do sexo masculino (CARVALHO, 2003, p. 186).

2 O salário-mínimo correspondia ao valor de duzentos reais.

$3 \mathrm{Na}$ época da pesquisa, o salário-mínimo era de duzentos e quarenta reais. 
Os modelos escolares de Educação de Jovens, Adultos e Idosos na cidade de São Paulo: Reflexões sobre demandas e ofertas

Entre a população economicamente ativa (PEA), os jovens eram os mais atingidos pelo desemprego, reforçando os mecanismos de exclusão social (SPÓSITO, 2003). A situação da juventude diante do mercado de trabalho é ambígua: ao mesmo tempo justifica seu afastamento da escola e seu retorno aos estudos para buscar a formação escolar básica para atender às oportunidades de emprego cada vez mais seletivas. Conforme a pesquisa de 2004, 47\% dos educandos retornou à escola para conseguir um emprego ou um emprego melhor, $32 \%$ dos estudantes indicaram a aprendizagem ou o desenvolvimento pessoal como motivos para voltarem aos estudos, sendo essas as maiores causas para aqueles acima de 46 anos (56\%) (SÃO PAULO, SME, 2004).

Em relação ao gênero observamos na pesquisa a presença de $55 \%$ de mulheres e $45 \%$ homens, sendo que, entre os homens, a maioria (51\%) tinha até 25 anos e entre mulheres, 64\% tinha mais de 25 anos. Eram mulheres casadas, separadas ou viúvas (55\%), tinham filhos menores de idade (54\%) e trabalhavam fora de casa (43\%) ou estavam desempregadas (34\%).

Os números confirmam a tendência das estatísticas nacionais, que demonstram que os meninos abandonam as escolas mais cedo que as meninas (CARVALHO, 2003). $\mathrm{O}$ afastamento e o retorno das mulheres às escolas em determinadas faixas etárias pode ser explicado devido à dificuldade de conciliarem a "maternagem" 4 com a vida escolar. A gravidez na adolescência pode também explicar o fato de as mulheres abandonarem a escola ainda no Ensino Fundamental e retornarem mais após 25 anos de idade, confirmando o papel tradicionalmente atribuído a elas no cuidado com a família.

Outro dado importante sobre o perfil dos estudantes relaciona-se à etnia. Embora a maioria da população brasileira (54\%) tenha se declarado branca e $44 \%$ negra (pretos ou pardos) no Censo de 2000. O percentual elevado de estudantes negros da EJA na pesquisa de 2004 (41\%) revela a desigualdade que historicamente marca essa população.

O que os dados revelam sobre o perfil dos sujeitos da EJA é que não apenas os estudantes adolescentes, como também adultos e idosos, mulheres e homens compartilham experiências de exclusão, vivenciam a difícil realidade das periferias da cidade, com moradias precárias, baixo acesso aos bens e equipamentos culturais, da carência de serviços de saúde e transporte na cidade. Eles frequentemente ocupam posições subalternas e possuem relações de trabalho informais, com baixos rendimentos. Sofrem e testemunham violência e preconceitos.

\footnotetext{
${ }^{4}$ Utilizamos o termo "maternagem" para designar o cuidado com os filhos, que ainda recai predominantemente sobre as mulheres mães.
} 
Daí que a procura pela escolarização por essa camada da população muitas vezes não seja a prioridade frente a outras demandas da vida familiar e societária, como confirmam os dados sobre aqueles que frequentaram a EJA em 2007 no Brasil, dos quais $42,7 \%$ não concluíram os estudos; 27,9\%, por não conciliá-los com os horários de trabalho ou de procurar trabalho e 15,6\%, pela falta de interesse (IBGE, 2009).

No cenário em que os direitos não são plenamente concretizados pelo Estado, as experiências dos jovens, adultos e idosos e suas expectativas sobre o acesso a serviços de saúde, cultura, melhor condição de trabalho etc. permeiam a relação entre sua escolarização e atuação profissional e cidadã, de modo que as iniciativas educativas que não dialogam com essa realidade concreta podem ter pouco ou nenhum sentido em suas vidas.

\section{Aspectos da oferta: os modelos escolares para EJA na cidade de São Paulo}

As ações do município de São Paulo para EJA compreendem diversas alternativas voltadas à modalidade na rede municipal de ensino. Desde 2003 até 2012, a EJA era realizada nas Escolas Municipais de Ensino Fundamental (EMEF) e Escolas Municipais de Ensino Fundamental e Médio (EMEFM), no Movimento de Alfabetização (MOVA), no Centro Municipal de Capacitação e Treinamento (CMCT), nos Centros Integrados de Educação de Jovens e Adultos (CIEJA) e na EJA Modular (a partir de 2011).

O MOVA atende educandos que estão na fase de alfabetização, em parceria com entidades sociais. Foi iniciado no governo de Luíza Erundina (PT) entre 1989 e 1992, interrompido nas gestões seguintes, até sua reativação no governo de Marta Suplicy (2001-2004). O MOVA funciona em salas instaladas em locais com grande demanda por alfabetização, em espaços como associações comunitárias, igrejas, creches, empresas. Depois de alfabetizados, os alunos são encaminhados para escolas públicas de São Paulo. As classes são agrupadas em núcleos e desenvolvem atividades presenciais, por 2 horas e meia, durante 4 dias da semana, de segunda a quinta-feira. A sexta-feira é reservada para formação de educadores / monitores (ABBONÍZIO, 2011).

Os CMTC foram idealizados para qualificação profissional de jovens e adultos e implantados no governo de Paulo Maluf (PDS), em 1995, com base nas demandas por formação profissional dos funcionários da prefeitura, sistematizadas no governo anterior. A cidade possui dois CMTC, que oferecem cursos de formação profissional inicial de 
Os modelos escolares de Educação de Jovens, Adultos e Idosos na cidade de São Paulo: Reflexões sobre demandas e ofertas

curta duração nas áreas de: panificação, confeitaria, elétrica residencial, mecânica de autos, informática, corte e costura e auxiliar administrativo. (SÃO PAULO, SME, 2012).

Atendem a modalidade EJA, com Ensino Fundamental, as escolas municipais (EMEF), a EJA Modular desde 2012 e os CIEJA desde 2003.

Nas EMEF, a EJA é oferecida no período noturno, das 19 h00 às 23 h00 horas. O curso é presencial, tem duração de 4 anos e está dividido, atualmente, em quatro Etapas: Etapa Alfabetização (2 semestres), Etapa Básica (2 semestres), Etapa Complementar (2 semestres) e Etapa Final (2 semestres). Nas EMEF, os cursos já foram anuais e semestrais e a organização dos horários se modificou em 2008, de acordo com a política para modalidade na época, que procurava aproximá-la do modelo dos CIEJA. No entanto, no ano seguinte retornaram ao modelo de organização mais tradicional das escolas.

A diversidade das propostas pouco tem refletido no número de matrículas da educação de jovens e adultos na cidade, que vem caindo, como demonstramos na tabela 1 da seção anterior. No entanto, verifica-se que houve um aumento de 12,03\% nas matrículas entre 2000 e 2004, período que coincide com a gestão de Marta Suplicy (20012004), em que se rearticulava o Movimento de Alfabetização (MOVA). Nesses anos foram implantados também os CIEJA, em substituição aos Centros Municipais de Ensino Supletivo (CEMES), pretendendo aliar a escolarização à qualificação profissional e atender às especificidades dos estudantes.

Até 2012, período estudado em nossa pesquisa, os CIEJA estavam distribuídos em 11 das 14 Diretorias Regionais da Educação, unidades administrativas da SME. Até o final de 2015, outros dois centros foram instalados, totalizando 16.

Considerados uma proposta "inovadora" entre as demais ofertas para EJA na cidade, os Centros também apresentaram queda no número de matrículas, desde que foram implantados em 2003 até 2012. No entanto, o decréscimo de 8,6 \% é significativamente menor que a redução de matrículas nas EMEF, de 62,9\% no mesmo período (CI/SME, 2012), conforme a tabela a seguir:

\footnotetext{
5 Termo que caracteriza o CIEJA nos pareceres do Conselho Municipal de Educação (CME) 81/06, aprovado em 24/08/06 e $\mathrm{n}^{\circ}$ 105/07, aprovado em 13/12/07. O mesmo se repete no documento de Reestruturação da EJA no Município (2008).
} 
Tabela 2- Evolução do número de matrículas em CIEJAs e EMEFs (2003/2012)

\begin{tabular}{|c|c|c|c|c|c|c|}
\hline \multicolumn{7}{|c|}{ MATRÍCULAS NOS CIEJAS e EMEFS } \\
\hline & \multicolumn{3}{|c|}{ MATRÍCULAS NOS CIEJAS } & \multicolumn{3}{|c|}{ MATRÍCULAS NAS EMEFs } \\
\hline Ano & EJA Anos Iniciais* & Anos Finais* & Total & EJA Anos Iniciais* & EJA Anos Finais* & Total \\
\hline 2003 & 5520 & 6822 & $12342 * \star \star$ & 27892 & 103760 & 131652 \\
\hline 2004 & 3561 & 8697 & 12258 & 28306 & 108125 & 136431 \\
\hline 2005 & 4381 & 9468 & 13849 & 27377 & 104545 & 131922 \\
\hline 2006 & 4206 & 8958 & 13164 & 22622 & 87849 & 110471 \\
\hline 2007 & 3869 & 7982 & 11851 & 17996 & 70763 & 88759 \\
\hline 2008 & 4306 & 9453 & 13759 & 18273 & 80562 & 98835 \\
\hline 2009 & 3813 & 8721 & 12534 & 15590 & 60236 & 75826 \\
\hline 2010 & 3612 & 8061 & 11673 & 13121 & 54093 & 67214 \\
\hline 2011 & 3576 & 7793 & 11369 & 10907 & 45845 & 56752 \\
\hline 2012 & 3195 & 8074 & 11269 & 9367 & 39454 & 48821 \\
\hline
\end{tabular}

Fonte: SME - Centro de Informática. Anos 2004 a 2012 - Censos MEC

* Os anos iniciais correspondem ao, então designados, Ciclo I do Ensino Fundamental, de $1^{\mathrm{a}}$ a $4^{\mathrm{a}}$ série e os anos finais ao Ciclo II, de $5^{\mathrm{a}} \mathrm{a} 8^{\mathrm{a}}$ série.

*** O total de matrículas em 2003 não contabiliza 2.927 matrículas nos anos iniciais em modalidade semipresencial, durante a transição entre CEMES-CIEJAs.

A diferença significativa entre a queda de matrículas nas EMEF e nos CIEJA pode ser explicada pelo fato de os centros possuírem um modelo escolar diferenciado, mais flexível e com a organização dos tempos, espaços e currículos voltados aos estudantes jovens, adultos e idosos. O desenvolvimento desse modelo escolar foi possível porque os CIEJA atravessaram diferentes governos com o estatuto de Projeto, que supunha avaliações e alterações anualmente autorizadas pelo Conselho Municipal de Educação, após relatórios da Diretoria de Orientações Técnicas (SÃO PAULO, DOT/EJA).

De 2003 (ano de sua implantação) a 2012, o Projeto foi desenhado em consonância com as especificidades dos estudantes e das necessidades próprias de organização para seu atendimento, vivenciadas nas unidades. Os Centros sofreram ameaças de fechamento entre as trocas de governos de Marta Suplicy (2001-2004) e José Serra/Gilberto Kassab (2005/2008), mas os funcionários, professores e gestores mobilizaram-se com os estudantes e atuaram junto à Secretaria Municipal de Educação, para manter seu funcionamento e peculiaridades, ao longo do tempo.

Das mobilizações resultou o desafio feito pelo então Secretário da Educação Alexandre Schneider, para que a Coordenadora Geral do CIEJA Campo Limpo, Êda Luiz, escrevesse o Projeto CIEJA, que já se desenvolvia em 14 unidades da cidade. Por meio do diálogo e da parceria com os demais Centros, Êda Luiz articulou a escrita do Projeto desde 2007 e a mobilização entre as unidades, bem como continuou até sua institucionalização, com a Lei 15.648 em 2012. 
Os modelos escolares de Educação de Jovens, Adultos e Idosos na cidade de São Paulo: Reflexões sobre demandas e ofertas

Em 2013, as 14 unidades de CIEJA então existentes na cidade possuíam 25\% das turmas de EJA no Ensino Fundamental do Município, enquanto as 256 EMEF que atendiam a modalidade possuíam $65 \%$ das $\operatorname{turmas}^{6}$ (SME, 2013).

Mas quais seriam as características desse modelo escolar, que apresentou menores quedas nas matrículas dos estudantes de EJA na cidade de São Paulo?

A primeira diferença que podemos apontar é que os CIEJA são centros de atendimento exclusivo para jovens, adultos e idosos, com a organização de espaços, turnos, currículo, gestão, secretaria, corpo docente, funcionários e funcionamento voltados apenas para o atendimento desse público. Isso significa que não é uma escola de crianças e adolescentes, com normas e formas de organização necessárias e peculiares, aos quais os educandos da EJA devem se adaptar. Esse fator influencia no desenvolvimento de atividades diversas, desde o atendimento das secretarias para buscas por informações e matrículas, até o controle de horários de entrada e saída dos educandos ou sua identificação com os espaços.

Os centros funcionam em turnos de duas horas e quinze minutos nos períodos: matutino, vespertino e noturno, e também diversificaram os tempos de estudo, buscando atender à diversidade dos estudantes: mães, avós, pessoas com deficiência, adolescentes, trabalhadores noturnos, trabalhadores diurnos etc.

Os cursos de Ensino Fundamental são organizados em quatro módulos anuais. Além de frequentarem sua turma em período específico, os alunos podem participar de atividades em turmas e horários diversificado, para repor aulas, integrar projetos e receber orientações de estudo, buscando possibilitar que conciliem suas obrigações pessoais com a vida estudantil.

Na busca por superar a hierarquia entre disciplinas e a fragmentação dos saberes, a proposta dos Centros é promover um currículo interdisciplinar, articulando três áreas do conhecimento: Linguagens e Códigos (Português, Inglês, Artes e Educação Física), Ciências Humanas (História e Geografia) e Ciências da Natureza e Matemática, além dos Itinerários Formativos, que visam integrar o Ensino Fundamental à formação profissional, que tiveram diferentes configurações ao longo dos anos, tendo permanecido em todos eles o de Informática.

\footnotetext{
${ }^{6}$ Dados Gerenciais da Secretaria Municipal de Educação, 2013. Fonte: Sistema ESCOLA ON-LINE e Sistema SIGPEC (RH) Data Base 30/MARÇO/2013.
} 
O currículo também incorpora atividades culturais em espaços diversificados, como museus, parques, teatros, centros comunitários etc., incentivando a circulação dos educandos pela cidade e aproveitamento dos saberes extraescolares.

Os CIEJA organizam-se segundo a gestão democrática, com o "incentivo e o reforço à participação das diferentes instâncias, internas e externas às unidades, é condição fundamental para maior qualificação na tomada de decisões" (SÃO PAULO, DOTEJA/SME-SP, 2004, p. 12).

As equipes são formadas pelo Coordenador Geral, Assistente de Coordenação Geral, Orientadores Pedagógicos Educacionais, Professores e Funcionários da rede municipal, concursados, selecionados e designados para os cargos. A seleção e designação especial, vigentes desde 2001 até 2012, visavam atrair e reter nos CIEJA profissionais preparados e identificados com sua proposta pedagógica e a modalidade EJA, na tentativa de garantir maior fixação ao quadro de servidores e propiciar o fortalecimento da construção coletiva das ações em cada unidade.

A equipe docente é também a responsável pela contextualização e criação de mecanismos para obtenção, sistematização e socialização do conhecimento em seus espaços coletivos de discussão. (SÃO PAULO, PARECER CME n 10/2002). Para tanto, os Centros garantem o Horário Coletivo ${ }^{7}$ obrigatório para todos os docentes, para a organização das rotinas escolares, o diálogo com as demandas estudantis, o planejamento e a avaliação das práticas, de maneira mais aproximada às necessidades e expectativas dos jovens, adultos e idosos.

Essas caraterísticas estruturantes delineadas no Projeto CIEJA são acompanhadas de outros Projetos e formas de organização, desenvolvidos em cada uma das unidades na cidade, em consonância com as especificidades de sua região e estudantes.

A flexibilização, a gestão democrática nos centros, o currículo interdisciplinar centrado na relação dos estudantes com a realidade e o desenvolvimento de sua autonomia favoreceram que o CIEJA tivesse se estabelecido, ao longo do tempo, como alternativa mais viável para uma série de jovens, adultos e idosos, que não se adaptaram ao modelo escolar tradicional, baseado no ensino das crianças e adolescentes.

\footnotetext{
${ }^{7}$ Os docentes, geralmente, submetem-se à Jornada Especial Integral de Formação (JEIF) que corresponde a 40 (quarenta) horas/aula semanais, sendo 25 (vinte e cinco) horas/aula de regência; 11 (onze) a serem cumpridas obrigatoriamente na escola e 04 (quatro), em local de livre escolha. Aqueles que não aderem a essa jornada de 40 horas/aula, complementam os horários de reunião como horas extras.
} 
Os modelos escolares de Educação de Jovens, Adultos e Idosos na cidade de São Paulo: Reflexões sobre demandas e ofertas

As experiências dos Centros influenciaram a formulação da EJA Regular, que funciona nas EMEF com projeto também diferenciado, cujo mote é a flexibilidade curricular. A EJA Modular é oferecida no período noturno em quatro Etapas: Alfabetização, Básica, Complementar e Final. Cada Etapa é composta por quatro módulos independentes e não sequenciais, com 50 dias letivos em encontros diários de 2 horas e 15 minutos (3 horas/aula). A complementação da carga horária diária, 1 hora e 30 minutos ( 2 horas/aula), é composta por atividades do enriquecimento curricular de presença optativa para estudantes.

\section{Considerações Finais}

É evidente que todas as propostas para a EJA existentes na cidade de São Paulo são importantes para o atendimento das necessidades e expectativas tão diversas quanto os sujeitos que as procuram; elas se complementam e oferecem diferentes alternativas de aprendizagem para jovens, adultos e idosos.

No entanto, essas alternativas ainda devem dialogar entre si, trocar experiências e saberes, umas com as outras, a fim de aprimorar cada vez mais suas formas de organização. A reflexão sobre as próprias práticas educativas, de que modo acolhem ou afastam educandos e educandas, possibilita sua renovação, inovação e adequação aos novos tempos. Esse diálogo, a partir da avaliação sobre os desafios e avanços locais, é que possibilitaria o desenvolvimento de propostas e currículos mais afinados com os sujeitos que retornam às escolas e têm na concretização do direito à educação uma porta de entrada para outros direitos humanos.

Nossa pesquisa avaliou que a participação das equipes escolares no desenho e na definição das políticas para EJA também é fundamental, para que elas sejam apropriadas e construídas com base nas experiências e nas realidades concretas das escolas e dos estudantes.

Finalmente, observamos que se ainda é grande a distância entre o número de matrículas da EJA e as pessoas com quinze anos ou mais com nenhuma ou pouca escolaridade, esforços vêm sendo realizados para estreitá-la, em espaços públicos comprometidos com o direito à educação, mesmo que conjuntamente sejam tímidos. $\mathrm{O}$ que não é mais possível é negar a existência de demanda ou lamentar a baixa procura pela modalidade EJA, sem questionar antes "Quem deveria procurar?" ou "Há baixa procura para qual modelo de ensino?" 


\section{REFERÊNCIAS BIBLIOGRÁFICAS}

ABBONÍZIO, A. C. de O. Orientações da parceria entre poder público e organizações sociais no MOVA-SP. 2007. Dissertação (Mestrado em Educação) Faculdade de Educação, Universidade de São Paulo, São Paulo, 2007. Disponível em: <http://www.teses.usp.br/teses/disponiveis/48/48134/tde-09102007-093437>. Acesso em: 16 out. 2011.

ARROYO, M. G. Gestão Democrática: recuperar sua radicalidade política? In: CORREA, B. C.; GARCIA, T. O. (Orgs.) Políticas Educacionais e organização do trabalho na escola. São Paulo: Xamã, 2008. p. 39-56.

BEISIEGEL, C. R. Estado e Educação Popular. Um estudo sobre a educação de adultos. São Paulo: Livraria Pioneira Editora, 1974.

BRANDÃO, C. R. Educação popular. São Paulo: Brasiliense, 1984.

BRASIL. SECRETARIA ESPECIAL DE DIREITOS HUMANOS DA PRESIDÊNCIA DA REPÚBLICA. Programa Nacional de Direitos Humanos (PNDH-3) / Brasília, 2010.

CARVALHO, M. P. de. Sucesso e fracasso escolar: uma questão de gênero. Educação e Pesquisa [online]. 2003, vol.29, n.1, p. 185-193 Disponível em:

<http://dx.doi.org/10.1590/S1517-97022003000100013 >. Acesso em: 21 out. 2011.

DI PIERRO, M. C. Descentralização, focalização e parceria: uma análise das tendências nas políticas públicas de educação de jovens e adultos. Educação e Pesquisa, São Paulo, v.27, n.2, p.321-337, jul./dez. 2001.

Luta social e reconhecimento jurídico do Direito Humano dos jovens e adultos à educação. Educação. Santa Maria, v. 33, n. 3, p. 395-410, set./dez. 2008.

GADOTTI, M. Educação de Adultos como Direito. São Paulo: Editora e Livraria Instituto Paulo Freire, 2009.

GÓES, M. De pé no chão também se aprende a ler (1961-1964): uma escola democrática. Rio de Janeiro: Civilização Brasileira, 1980.

GRINKRAUT, A.; NAKAGAWA, C.; CAMPAGNUCCI, F.; SILVA U. Panorama das desigualdades na cidade de São Paulo. Em questão. São Paulo, n. 8, p. 25-114, 2013. $1^{\text {a }}$ Edição.

HADDAD, S. Novos Caminhos em educação de Jovens e Adultos - EJA: um estudo de ações do poder público em cidades de regiões metropolitanas brasileiras. São Paulo: Global Editora, 2007.

INSTITUTO BRASILEIRO DE GEOGRAFIA E ESTATÍSTICA. Síntese de Indicadores Sociais: Uma Análise das Condições de Vida da População Brasileira 2009. Rio de Janeiro: IBGE, 2010. 
Síntese de Indicadores Sociais: Uma Análise das Condições de Vida da População Brasileira 2012. Rio de Janeiro: IBGE, 2012.

RIBEIRO, V. M. Traçando o perfil de alunos e professores da EJA. São Paulo: Secretaria Municipal de Educação de São Paulo. Diretoria de Orientação Técnica. Divisão de Educação de Jovens e Adultos, 2004.

SÃO PAULO. SECRETARIA MUNICIPAL DE EDUCAÇÃO. CIEJA - Centro Integrado de Educação de Jovens e Adultos. Relatório de Pesquisa. Perfil do contexto dos Centros. São Paulo, 2002.

SÃO PAULO. SECRETARIA MUNICIPAL DE EDUCAÇÃO. SENAC- SP. CIEJA Centro Integrado de Educação de Jovens e Adultos. São Paulo, 2002.

Revista do CIEJA. Diferentes olhares sobre a prática curricular no CIEJA.

São Paulo, 2004.

SÃO PAUlO. CONSELHO MUNICIPAL DE EDUCAÇÃO. Parecer CME $\mathbf{n}^{\circ}$ 10/2002 -CEB- Aprovado em 07/11/2002. Diretoria de Orientação Técnica da Educação de Jovens e Adultos da Secretaria Municipal de Educação (DOT/SME). Autorização de funcionamento do Centro Integrado de Educação de Jovens e Adultos - CIEJA.

SPOSITO, M. P. Os jovens no Brasil: desigualdades multiplicadas e novas demandas políticas. São Paulo: Ação Educativa, 2003. Disponível em: $\langle$ http://www.bdae.org.br/dspace/bitstream/123456789/2345/1/Jovens_Brasil.pdf>. Acesso em: 25 mai. 2016.

Recebido em: 22/02/2016

Aprovado em: 22/05/2016 